\title{
Mechanistic Insight into the Catalytic NO Oxidation by the MIL-100 MOF Platform: Towards the Prediction of More Efficient Catalysts
}

Pengbo Lyu and Guillaume Maurin*

ICGM, Univ. Montpellier, CNRS, ENSCM, Montpellier, France

Corresponding Author

Guillaume Maurin (guillaume.maurin1@umontpellier.fr) 


\section{Computational details}

The unrestricted B3LYP exchange-correlation functional was used for all calculations with the Gaussian 09 program suite. ${ }^{1}$ The $\mathrm{TZVP}^{2}$ basis set was employed for all atoms except for $\mathrm{Ru}$ which was treated by the LANL2DZ ${ }^{3}$ basis set. The DFT-D3 method ${ }^{4}$ was used to include the dispersion correction. The transition states were located using the keyword TS. Frequency calculations have been performed for all minima and transition states to ensure no imaginary frequencies for minima and only one imaginary frequeny for each transition states. The Hirshfeld charges were obtained with Multiwfn, ${ }^{5}$ as well as the DOS plots brodened from energy levels. The numbers of unpaired electrons for each stable structure optimized are shown in Table S1.

Table S1. The numbers of unpaired electrons for each stable structure along reaction path in Figure 1, 2, 3 and Figure S9

\begin{tabular}{ccccccccc}
\hline Structure & $\mathrm{Al}(\mathrm{III})$ & $\mathrm{Fe}(\mathrm{III})$ & $\mathrm{Fe}(\mathrm{II})$ & $\mathrm{V}(\mathrm{III})$ & $\mathrm{Mn}(\mathrm{II})$ & $\mathrm{Ru}(\mathrm{III})$ & $\mathrm{Ti}(\mathrm{III})$ & $\mathrm{Cr}(\mathrm{III})$ \\
\hline cluster & 0 & 5 & 4 & 2 & 5 & 5 & 1 & 3 \\
IS & 1 & 4 & 5 & 1 & 4 & 4 & 0 & 2 \\
TS1 & 1 & 4 & 5 & 1 & 4 & 4 & 0 & 2 \\
INT1 & 1 & 4 & 5 & 1 & 4 & 4 & 0 & 2 \\
INT2 & 1 & 4 & 5 & 1 & 4 & 4 & 0 & 2 \\
INT2' & 2 & 5 & 4 & 2 & 3 & 5 & 1 & 1 \\
INT3 & 0 & 5 & 4 & - & 5 & 5 & 1 & 3 \\
INT3' & - & - & - & 1 & - & - & - & - \\
TS2 & 0 & 5 & 4 & - & 5 & 5 & 1 & 3 \\
TS2' & - & - & - & 1 & - & - & - & - \\
FS & 0 & 5 & 4 & - & 5 & 5 & 1 & 3 \\
FS' & 1 & 4 & 5 & 1 & 4 & 4 & 0 & 2 \\
\hline
\end{tabular}



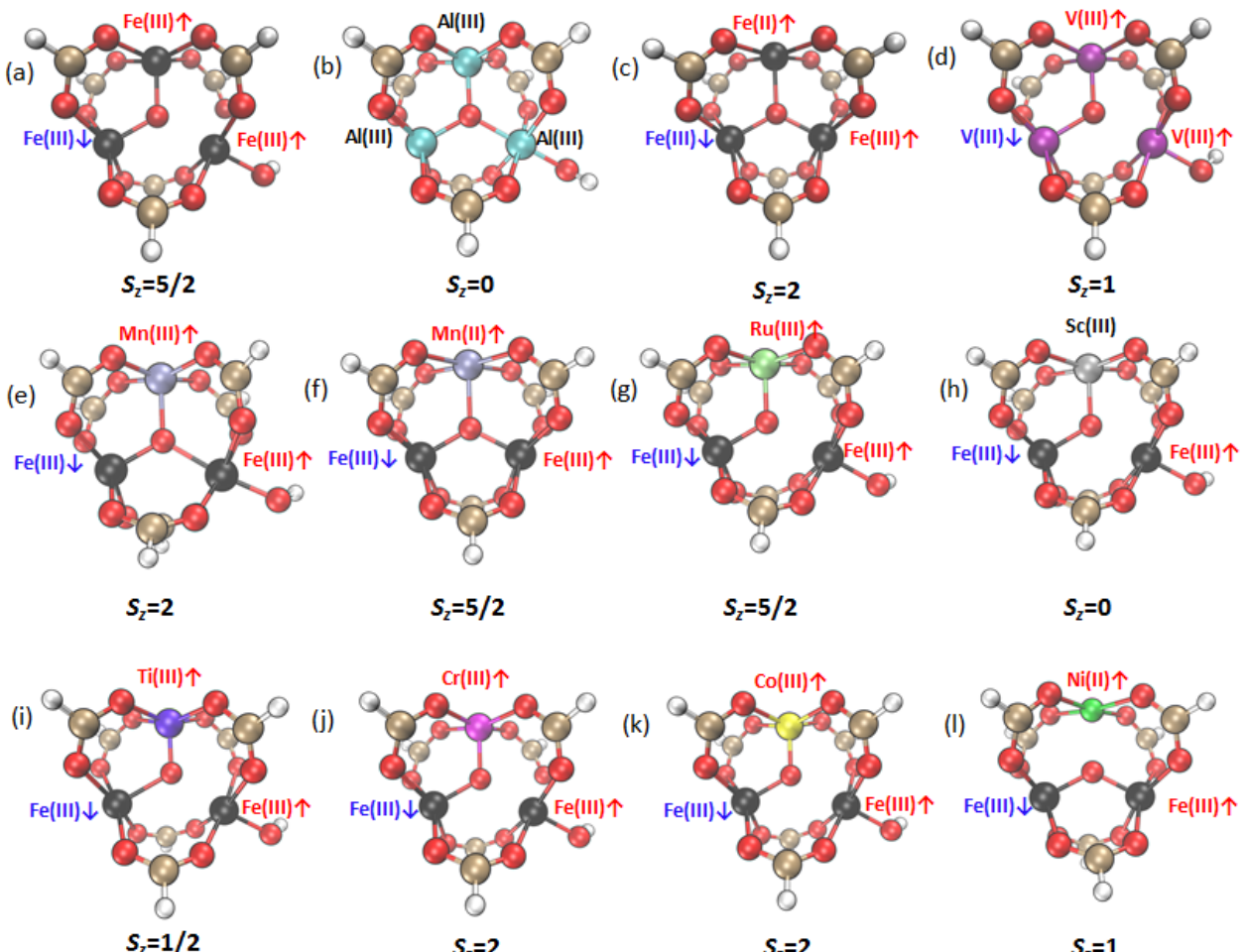

$$
s_{2}=5 / 2
$$

$$
s_{2}=0
$$

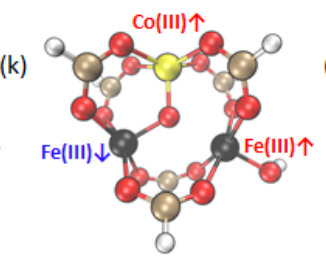

$S_{2}=2$

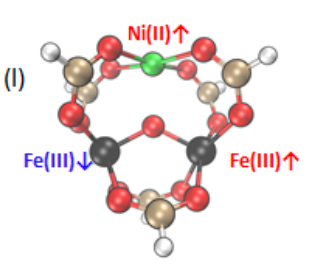

$s_{z}=1$

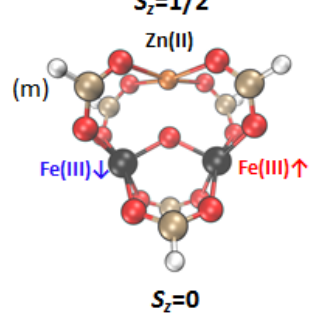

Figure S1. Most stable electronic configurations found for (a) $\mathrm{Fe}(\mathrm{III})_{3}$, (b) $\mathrm{Al}(\mathrm{III})_{3}$, (c) $\mathrm{Fe}(\mathrm{II}) \mathrm{Fe}(\mathrm{III})_{2}$, (d) $\mathrm{V}(\mathrm{III})_{3}$, (e) $\mathrm{Mn}(\mathrm{III}) / \mathrm{Fe}$ (III), (f) $\mathrm{Mn}$ (II)/Fe(III), (g) Ru(III)/Fe(III), (h) Sc(III)/Fe(III), (i) Ti(III)/Fe(III), (j) $\mathrm{Cr}(\mathrm{III}) / \mathrm{Fe}(\mathrm{III}),(\mathrm{k})$ $\mathrm{Co}(\mathrm{III}) / \mathrm{Fe}(\mathrm{III}),(\mathrm{l}) \mathrm{Ni}(\mathrm{II}) / \mathrm{Fe}(\mathrm{III})$ and (m) $\mathrm{Zn}(\mathrm{II}) / \mathrm{Fe}(\mathrm{III})$ oxo-trimers. Colors code: carbon (grey), oxygen (red), hydrogen (white), nitrogen (blue), aluminium (cyan), iron (black), vanadium (purple), manganese (iceblue), ruthenium (lime), scandium (gray), titanium (violet), chromium (magenta), cobalt (yellow), nickel (green) and zinc (orange). 


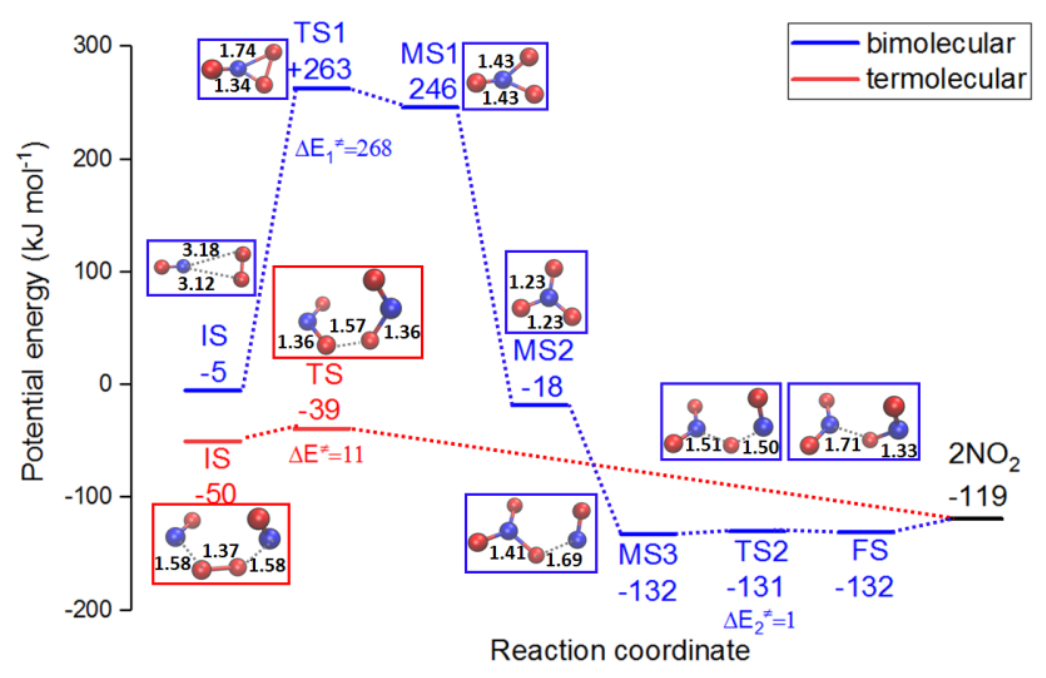

Figure S2. Bimolecular and ter-molecular reaction paths of NO oxidation in gas phase. Distances are in Å. Colors code: carbon (grey), oxygen (red), hydrogen (white) and nitrogen (blue).

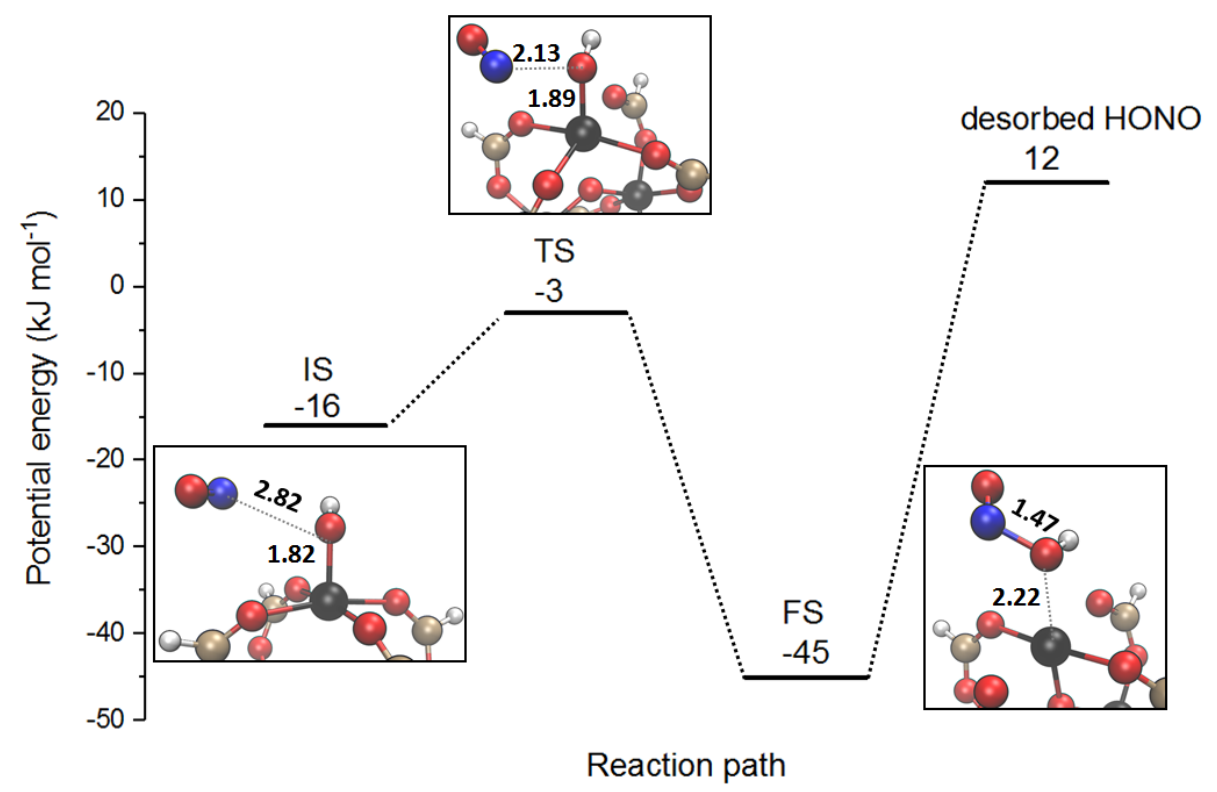

Figure S3. Reaction path of Fe(II)/Fe(III) oxo-trimer formation. Colors code: carbon (grey), oxygen (red), hydrogen (white), nitrogen (blue) and iron (black). Distances are in $\AA$. 

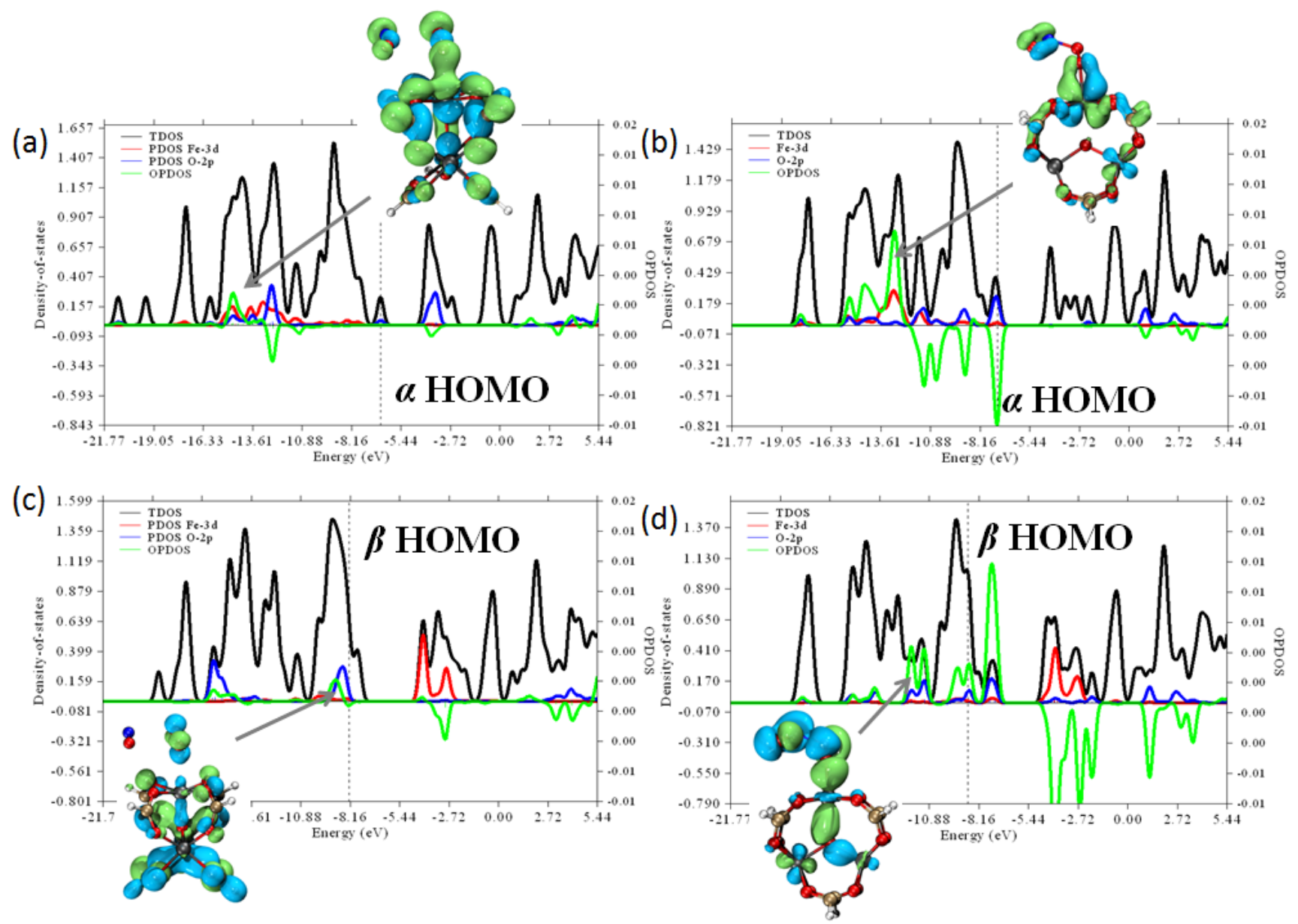

Figure S4. Total DOS, projected DOS (PDOS) on Fe $3 d$ and O $2 p$ orbitals and the overlap population DOS (OPDOS) for $\mathrm{Fe}(\mathrm{III})$ (a and c) and $\mathrm{Fe}(\mathrm{II})$ ( $\mathrm{b}$ and d) of the oxo-trimer. The molecular orbitals corresponding to most positive OPDOS are equally shown (iso-values $0.03 \mathrm{e}^{-} / \AA^{3}$ ). 

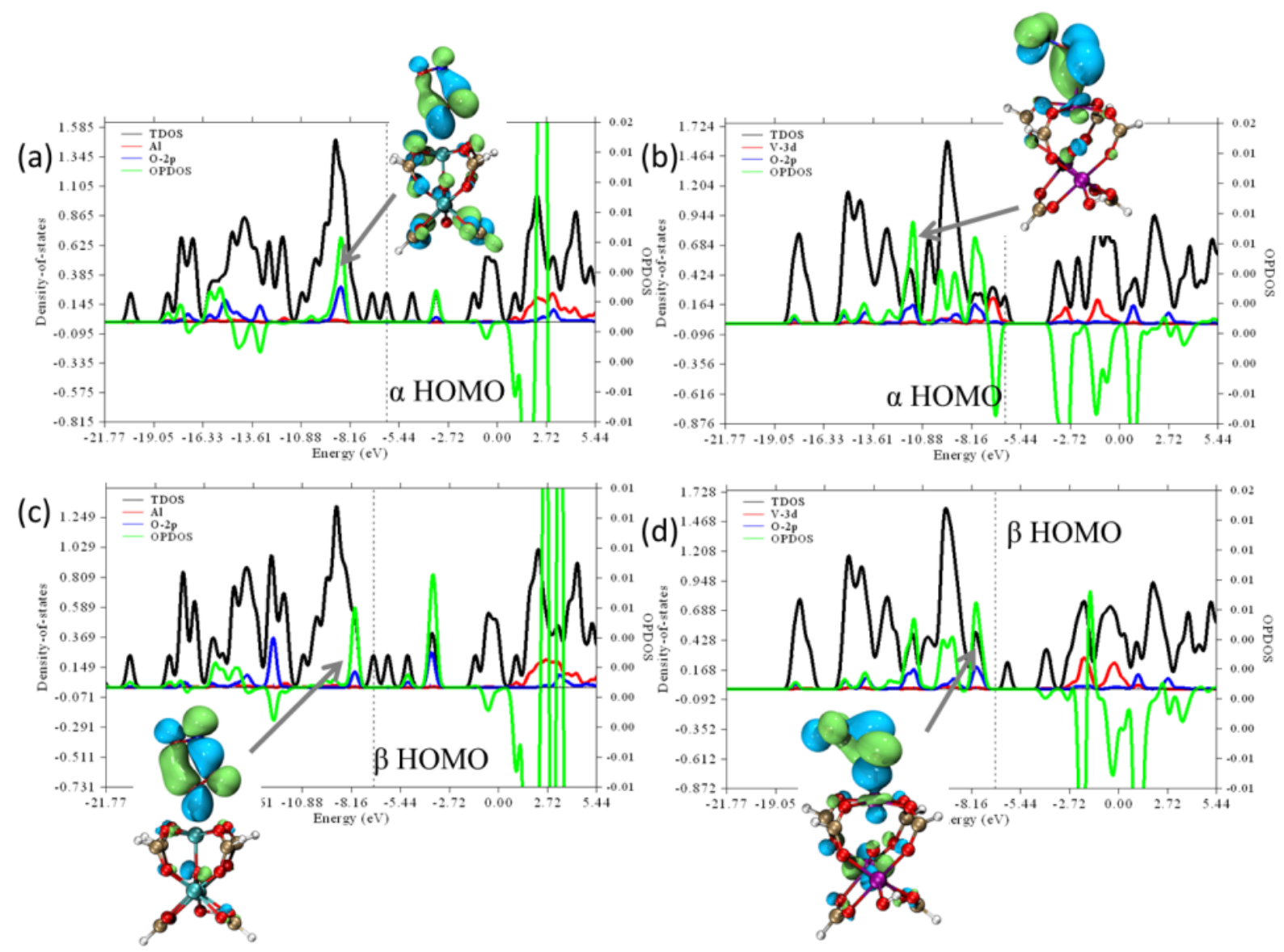

Figure S5. The total DOS, projected DOS (PDOS) on $\mathrm{Al} 3 \mathrm{~s} / \mathrm{V} 3 \mathrm{~d}$ and O $2 \mathrm{p}$ orbitals and the overlap population DOS (OPDOS) between $\mathrm{Al} 3 \mathrm{~s} / \mathrm{V} 3 \mathrm{~d}$ and $\mathrm{O} 2 \mathrm{p}$ orbitals (the sum of $\mathrm{O}_{2}$ ) for IS over $\mathrm{Al}(\mathrm{III})((\mathrm{a})(\mathrm{c})$ ) and $\mathrm{V}(\mathrm{III})((\mathrm{b})(\mathrm{d})$ ) of the corresponding oxo-trimers. The molecular orbitals corresponding to most positive OPDOS are equally shown (isovalues $\left.0.03 \mathrm{e}^{-} / \AA^{3}\right)$. 

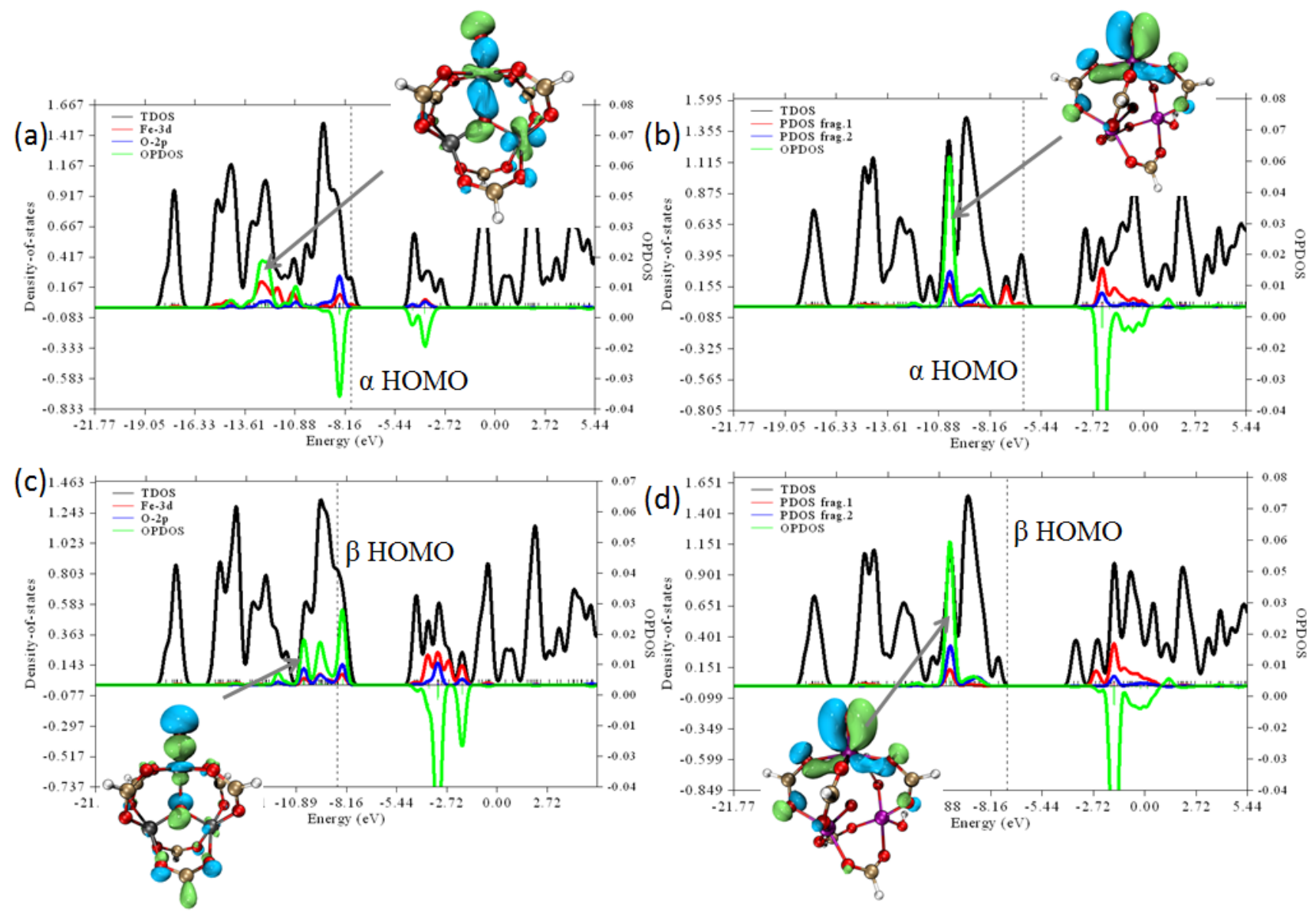

Figure S6. The total DOS, projected DOS (PDOS) on Fe 3d and O $2 p$ orbitals and the overlap population DOS (OPDOS) between metal $3 \mathrm{~d}$ and O 2p orbitals for INT2' on Fe (II)((a)(c)) and V(III) ((b)(d)) of the corresponding oxo-trimers. The molecular orbitals corresponding to most positive OPDOS are equally shown (iso-values 0.03 $\left.\mathrm{e}^{-} / \AA^{3}\right)$. 


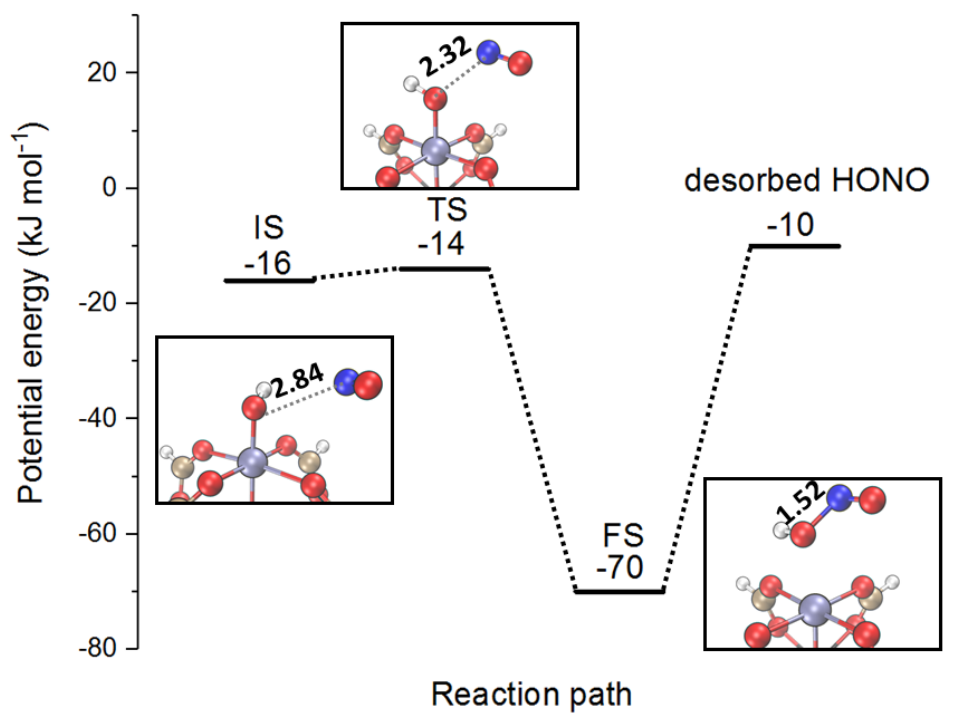

Figure S7. Reaction path of $\mathrm{Mn}(\mathrm{II}) / \mathrm{Fe}(\mathrm{III})$ oxo-trimer formation. Colors code: carbon (grey), oxygen (red), hydrogen (white) , nitrogen (blue) and manganese (ice blue). The distances are reported in $\AA$.

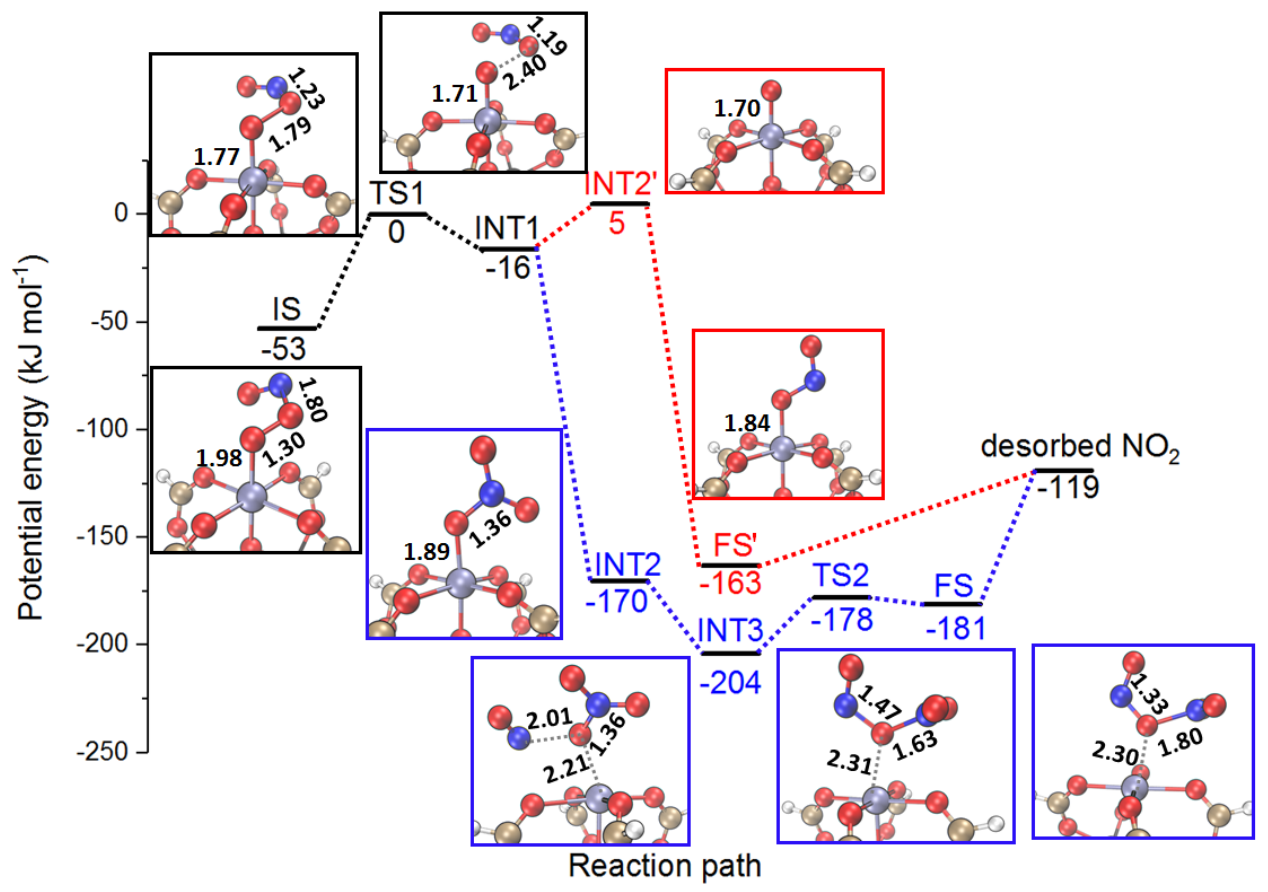

Figure S8. Potential energy profiles for NO oxidation catalyzed by $\mathrm{Mn}(\mathrm{II}) / \mathrm{Fe}(\mathrm{III})$ oxo-trimers. The separated clusters and reactant molecules in the gas phase are taken as zero point of potential energy. Colors code: carbon (grey), oxygen (red), hydrogen (white), nitrogen (blue) and manganese (iceblue). The distances are reported in $\AA$. 


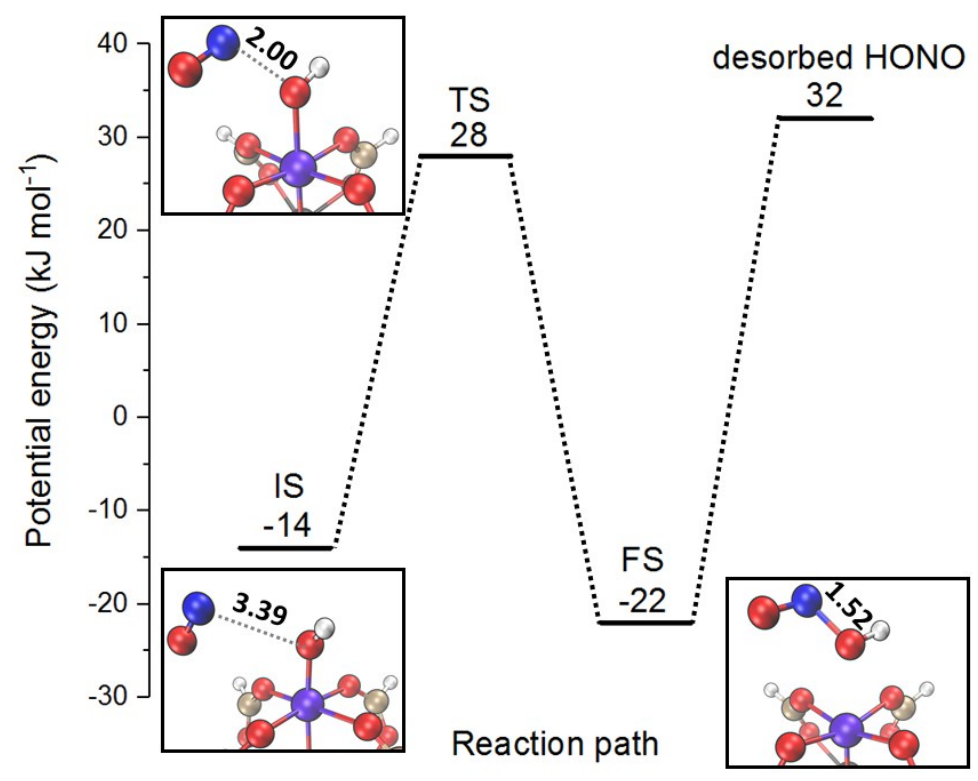

Figure S9. Reaction path of $\mathrm{Ti}(\mathrm{III}) / \mathrm{Fe}(\mathrm{III})$ oxo-trimer formation. Colors code: carbon (grey), oxygen (red), hydrogen (white), nitrogen (blue) and titanium (violet). The distances are reported in $\AA$.

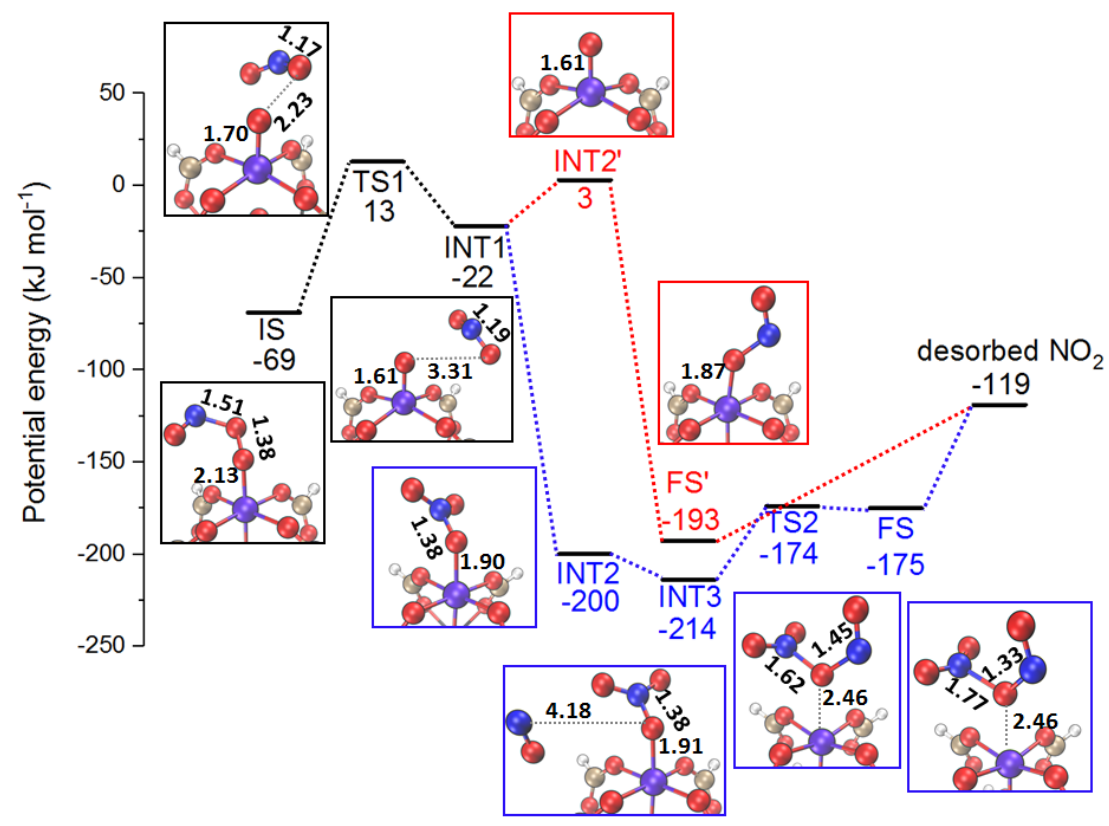

Figure S10. Potential energy profiles for NO oxidation catalyzed by $\mathrm{Ti}(\mathrm{III}) / \mathrm{Fe}(\mathrm{III})$ oxo-trimers. The separated clusters and reactant molecules in the gas phase are taken as zero point of potential energy. Colors code: carbon (grey), oxygen (red), hydrogen (white), nitrogen (blue) and titanium (violet). The distances are reported in $\AA$. 


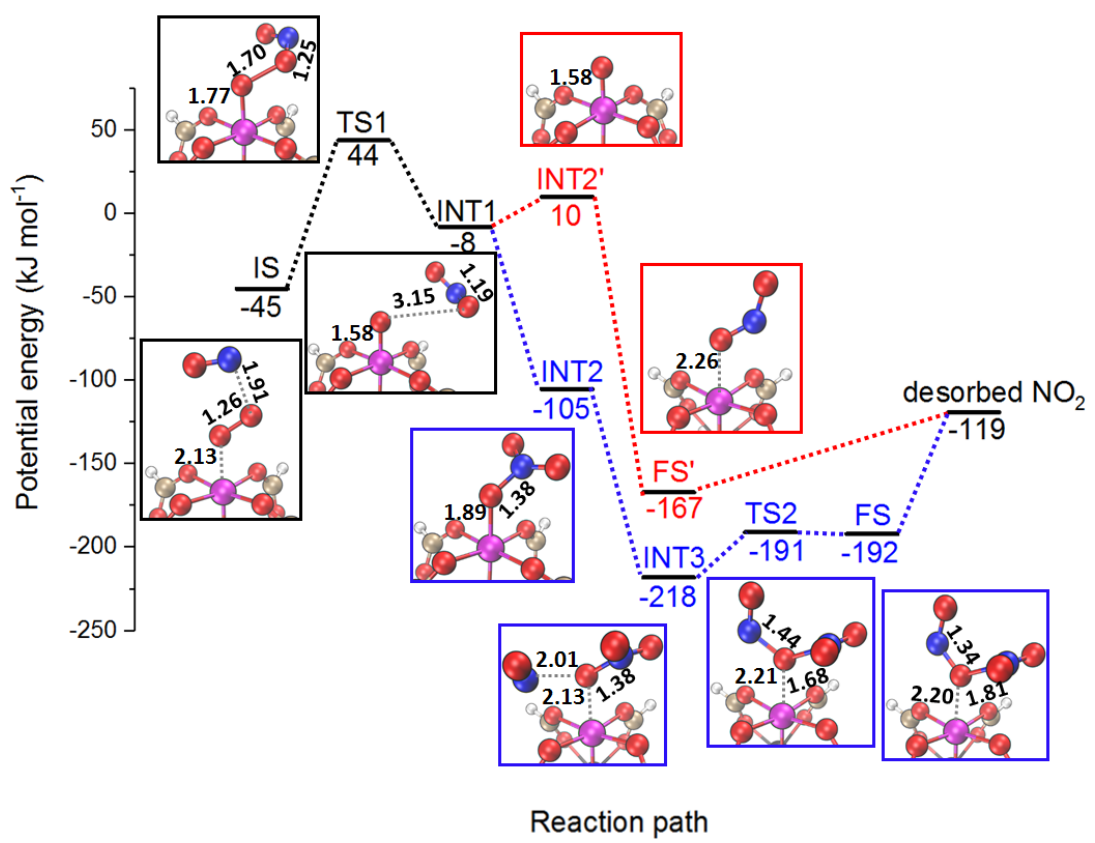

Figure S11. Potential energy profiles for NO oxidation catalyzed by $\mathrm{Cr}(\mathrm{III}) / \mathrm{Fe}(\mathrm{III})$ oxo-trimers. The separated clusters and reactant molecules in the gas phase are taken as zero point of potential energy. Colors code: carbon (grey), oxygen (red), hydrogen (white), nitrogen (blue) and chromium (magenta). The distances are reported in $\AA$.

\section{Reference}

(1) Frisch, M. J.; et al. Gaussian 09 Rev. D.01, Gaussian, Inc.: Wallingford, CT, 2016.

(2) Schäfer, A.; Huber, C.; Ahlrichs, R. Fully optimized contracted Gaussian basis sets of triple zeta valence quality for atoms Li to Kr. J. Chem. Phys. 1994, 100, 5829-5835.

(3) Hay, P. J.; Wadt, W. R. Ab initio effective core potentials for molecular calculations. Potentials for K to Au including the outermost core orbitals. J. Chem. Phys. 1985, 82, 299-310.

(4) Grimme, S.; Antony, J.; Ehrlich, S.; Krieg, H. A consistent and accurate ab initio parametrization of density functional dispersion correction (DFT-D) for the 94 elements H-Pu. J. Chem. Phys. 2010, 132, 154104.

(5) Lu, T.; Chen, F. Multiwfn: A multifunctional wavefunction analyzer. J. Comput. Chem. 2012, 33, 580-592. 